\title{
Perspectives about the use of autografts and allografts for the acetabular component of a total hip arthroplasty
}

\begin{abstract}
Autografts and allografts have been valuable for the reconstruction of the acetabulum both in primary and revision surgery of total hip arthroplasty. The increasing use of highly porous metals supplements could decrease its indication in the future. The present article reviews its indications.
\end{abstract}

Volume 6 Issue 3 - 2016

\author{
Jenaro A Fernández-Valencia, Xavier Gallart, \\ Guillem Bori, Ernesto Muñoz Mahamud, \\ Josep Riba, Andreu Combalia \\ Department of Orthopaedic and Trauma Surgery, Hospital \\ Clinic of Barcelona, Spain
}

\begin{abstract}
Correspondence: Jenaro Fernandez-Valencia, Senior Orthopaedic Surgeon, Clinical Professor, Hip Unit, Department of Orthopaedic and Trauma Surgery, Hospital Clinic, Barcelona Villarroel, 170 - 08036, Barcelona, Spain, Tel (+34)932275533, Email jenarofv@clinic.ub.es
\end{abstract}

Received: August 26, 2016 | Published: November 9, 2016

\section{Introduction}

Acetabular defects can occur at the original arthritic process; this is commonly seen in dysplastic hips, but also as a late complication of failed cases of trauma or infections. In the setting of revision surgery, prosthetic failure and migration, and/or osteolysis from cement or polyethylene wear particles can produce severe acetabular defects. Also, and not openly reported in literature, the own bone removal of a well fixed cup can produce serious defects, especially when the technique is performed without specific tools of without enough skills.

\section{Acetabular defects in the arthritic hip}

The bone defect caused by the arthritic process can be addressed using bone autograft from the own removed femoral head. This is the case for hip dysplasia or for rapid progressive osteoarthritis. For Crowe type II and III hips, the placement an autogenous superior lateral bone augmentation, has provided satisfactory results. ${ }^{1}$ This technique allows restoring the biomechanical normal position of the center of rotation of the hip and increases bone stock, being this an advantage for an eventual future revision. According to Gerber and Harris ${ }^{2}$ and Mulroy and Harris, ${ }^{3}$ autogenous grafting had a high risk of collapse at the long term follow-up. Although all the grafts united initially, resorption occurred by late revascularization and creeping substitution. In these series, the acetabular rate of failure was $21 \%$ after seven years and $46 \%$ after 12 . More favorable series show a successful reconstruction such as $93,9 \%$ at 8,3 years ${ }^{4}$ or $94 \%$ at 10 years. ${ }^{5}$ In order to avoid failure, it has been stated that the most important factor fur success is to restore the anatomical center of rotation of the hip. ${ }^{6}$ Another option is to restore the center of rotation and to obtain coverage using a metal supplement. We are increasingly using this option in our practice and recently published our results, by using Trabecular Titanium ${ }^{\mathrm{TM}}$ (TT) cups in selected primary total hip arthroplasty cases. The advantage is the simplification and reproducibility of the surgical procedure, the enhanced stability that it provides, and in the long term to prevent collapse. The inconvenient, being the same in the revision setting, would come from the difficulty of handling with this piece of metal in a possible future revision: the removal, if needed, could provoke a worse bone defect. But also, due to the modularity, in some cases this piece could be retained to aid for the reconstruction (Figure 1). Future studies have to compare the results of the use of allograft versus highly porous metal augments for primary cases with acetabular bone defects.

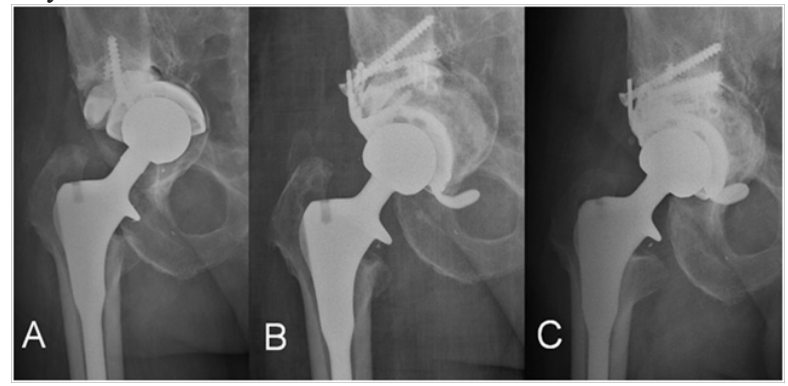

Figure I A Image depicting a cup loosened with a Paprosky type 3B defect. In this case we trabecular titanium supplement was found to be stable and was kept in place, and we decided to add a bulk structural allograft with a Delta TT cup (Lima Corporate) with flanges.

Figure IB The evolution was satisfactory and shown in the postoperative images.

Figure IC One year follow-up.

\section{Acetabular defects in the revision total hip arthroplasty}

In this setting, the use of bone allografs continues to be valuable. Impaction bone grafting provides satisfactory results for contained defects. It can also be applied to uncontained defects after reconstruction with meshs. The size of the morsecilled fragments is important. While in proximal femoral revision it has been recommended a size between 3 and $5 \mathrm{~mm}$ on the acetabular side, the ideal size is larger; research suggests that 8 to 10 -mm-diameter chips provide the best initial stability. ${ }^{6}$ The use of allograft is somehow feared by some surgeons or patients due to an increased risk of infection. However it is uncommon and it merits mentioning that in the register of allografts in UK it has never been reported. ${ }^{7}$ 
Managing severe acetabular bone defects during revision hip arthroplasty remain a great challenge, are controversial, and many different options are used, such as: impaction bone grafting with reinforcement ring and cemented cup ${ }^{8}$ metal mesh \& impaction bone grafting and cemented cup, ${ }^{9}$ acetabular reinforcement ring, ${ }^{10,11}$ oblong cup, ${ }^{12,13}$ uncemented cup with high hip center ${ }^{14}$ structural allograft with reinforcement devices, ${ }^{15}$ tantalum trabecular metal ${ }^{\mathrm{TM}} \mathrm{o}$ trabecular titanium $^{\mathrm{TM}}$ cups with augment. ${ }^{16-18}$ The main advantage of using allografts is that you can adjust the graft to the defect, and we keep its use for some complex cases, especially in the young patient, in which a restoration of the bone stock is desirable for the future. However, we have observed that incorporation of the structural grafts is not the rule when observed by CT scan. ${ }^{19}$ At our practice, we have observed a tendency to decrease the use of structural allograft in favour of trabecular metal ${ }^{\mathrm{TM}} \mathrm{o}$ trabecular titanium ${ }^{\mathrm{TM}}$ cups with augments.

\section{Conclusion}

Both autografts and allografts are still valuable. But highly porous metals can be considered in the indications in which previously no alternative option was available, and excellent results are being published. We consider that for many cases, and progressively, highly porous metal augments will substitute the use of autografts and allografts, but especially for allografts in the revision setting.

\section{Acknowledgements}

None.

\section{Conflicts of interest}

None.

\section{References}

1. Sanchez-Sotelo J, Berry DJ, Trousdale RT, et al. Surgical treatment of developmental dysplasia of the hip in adults: II. Arthroplasty options. $J$ Am Acad Orthop Surg. 2002;10(5):334-344.

2. Gerber SD, Harris WH. Femoral head autografting to augment acetabular deficiency in patients requiring total hip replacement. A minimum fiveyear and an average seven-year follow-up study. J Bone Joint Surg Am. 1986;68(8):1241-1248

3. Mulroy RD, Harris WH. Failure of acetabular autogenous grafts in total hip arthroplasty. Increasing incidence: a follow-up note. J Bone Joint Surg Am. 1990;72(10):1536-1540.

4. Atilla B, Ali H, Aksoy MC, et al. Position of the acetabular component determines the fate of femoral head autografts in total hip replacement for acetabular dysplasia. J Bone Joint Surg Br. 2007;89(7):874-878.

5. Kim M, Kadowaki T. 2010;High long-term survival of bulk femoral head autograft for acetabular reconstruction in cementless THA for developmental hip dysplasia. Clin Orthop Relat Res. 468(6):1611-1620.
6. Holton $\mathrm{C}$, Bobak P, Wilcox R, et al. Impaction grafted bone chip size effect on initial stability in an acetabular model: Mechanical evaluation. J Orthop. 2013;10(4):177-181.

7. Lomas R, Chandrasekar A, Board TN. Bone allograft in the UK: perceptions and realities. Hip Int. 2013;23(5):427-433.

8. Peters CL, Curtain M, Samuelson KM. Acetabular revision with the Burch-Schnieder antiprotrusio cage and cancellous allograft bone. $J$ Arthroplasty. 1995;10(3):307-312.

9. Buttaro MA, Comba F, Pusso R, et al. Acetabular revision with metal mesh, impaction bone grafting, and a cemented cup. Clin Orthop Relat Res. 2008;466(10):2482-2490.

10. Gerber A, Pisan M, Zurakowski D, et al. Ganz reinforcement ring for reconstruction of acetabular defects in revision total hip arthroplasty. $J$ Bone Joint Surg Am. 2003;85A(12):2358-2364.

11. Hori J, Yasunaga Y, Yamasaki T, et al. Mid-term results of acetabular reconstruction using a Kerboull-type acetabular reinforcement device. Int Orthop. 201236(1):23-26.

12. Civinini R, Capone A, Carulli $\mathrm{C}$, et al. Acetabular revisions using a cementless oblong cup: five to ten year results. Int Orthop. 2008;32(2):189-193.

13. Köster G, Rading S. Revision of failed acetabular components utilizing a cementless oblong cup: an average 9-year follow-up study. Arch Orthop Trauma Surg. 2009;129(5):603-608.

14. Kelley SS. High hip center in revision arthroplasty. J Arthroplasty. 1994;9:503-510.

15. O'Rourke MR, Paprosky WG, Rosenberg AG (2004) Use of structural allografts in acetabular revision surgery. Clin Orthop Relat Res. 1994;420:113-121.

16. Abolghasemian M, Tangsataporn S, Sternheim A, et al. Combined trabecular metal acetabular shell and augment for acetabular revision with substantial bone loss: a mid-term review. Bone Joint. 2013;J.95B:166-172.

17. Flecher X, Sporer S, Paprosky W. Management of Severe Bone Loss in Acetabular Revision Using a Trabecular Metal Shell. J Arthroplasty. 200823(7):949-955.

18. Gallart X, Fernández-Valencia JA, Riba J,et al. Trabecular TitaniumTM cups and augments in revision total hip arthroplasty: clinical results, radiology and survival outcomes. Hip Int. 2008;26(5):486-491.

19. Fernandez-Valencia JÁ, Gallart X, Tomás X, et al. adiography versus multidetector computed tomography in assessing graft integration after acetabular reconstruction. J Orthop Surg (Hong Kong). 2015;23(3):370-374. 